Bol. Acad. peru. leng. 56. 2013 (41-51)

\title{
POSIBLE INCLUSIÓN EN LOS DICCIONARIOS DE NUEVAS PALABRAS FORMADAS A PARTIR DE LOS DIVERSOS PROCEDIMIENTOS EXISTENTES*
}

\section{DE LA POSSIBLE INCLUSION DANS LES DICTIONNAIRES DE MOTS NOUVEAUX FORMÉS À PARTIR DES DIVERS PROCÉDÉS EXISTANTS}

\section{POSSIBLE INCLUSION IN DICTIONARIES OF NEW WORDS FORMED FROM THE VARIOUS EXISTING PROCEDURES}

\author{
José Luis Samaniego Aldazábal \\ Comisión de Gramática \\ Academia Chilena de la Lengua
}

\section{Resumen:}

Proponemos plantear la necesidad de que el lexicógrafo, como hacedor de diccionarios, incluya nuevas palabras de origen no solamente lexicogenésico, sino que considere también las que están formadas por acortamientos, los extranjerismos, los acrónimos, etc. Este tema es parte de la elaboración de una gramática que adapta la doctrina de la Nueva gramática de la lengua española a la tradición gramatical vigente en Chile pensando, sobre todo, en los profesores de lengua.

Ponencia presentada en el VIII Congreso Internacional de Lexicología y Lexicografía en Homenaje a Martha Hildebrandt Pérez Treviño, realizado del 9 al 11 de octubre de 2013. 


\section{Résumé:}

Nous soutenons ici qu'il est nécessaire que le lexicographe, en tant que créateur de dictionnaires, inclue de nouveaux mots d'origine non seulement lexicogénique, mais qu'il considère aussi les mots formés par troncation, les mots étrangers, les acronymes, etc. Ce sujet fait partie de l'élaboration d'une grammaire qui adapte la doctrine de la Nouvelle Grammaire de la Langue Espagnole (Nueva gramática de la lengua española) à la tradition grammaticale en vigueur au Chili, en pensant, surtout, aux professeurs de langue.

\section{Abstract:}

We propose that lexicographers as dictionary makers, need to include not only new words of lexicogenetic origin, but also they should consider those words formed from shortenings, foreign words, acronyms, etc. This topic is part of the preparation of a grammar that adapts the doctrine of the New Grammar of the Spanish Language to the existing grammatical tradition in Chile, thinking in particular of language teachers.

Palabras clave: diccionarios; acortamientos; extranjerismos; acrónimos.

Mots clés: dictionnaires; troncation; emprunts lexicaux; acronymes.

Key words: dictionaries; shortenings; foreign words; acronyms.

Fecha de recepción:

Fecha de aceptación:
$11 / 10 / 2013$

$28 / 10 / 2013$

El propósito de esta presentación es doble. Por una parte, subrayar como tarea propia del lexicógrafo la necesidad que tiene de sopesar la conveniencia o no conveniencia de incorporar al diccionario oficial o bien a los diccionarios regionales o nacionales el nuevo léxico en uso, sea que se forme por vía externa, como es el caso de los préstamos, o por vía interna. Esta última ya sea que corresponda a creación morfológica o a creación semántica a partir de determinadas unidades léxicas de nuestra propia lengua, de algún préstamo extranjero o de los elementos 
compositivos cultos, procedentes de las canteras del español, el griego y el latín. Existe también un segundo propósito, el cual consiste en proponer ciertas distinciones teórico-metodológicas que nos han surgido del análisis mismo de algunos de los planteamientos propuestos por la Nueva gramática de la lengua española.

En la exposición de nuestro trabajo incluiremos los puntos siguientes:

1. Procesos morfológicos.

2. Procedimientos por reducción.

3. Caso de extranjerismos.

4. Fijación léxica.

5. Creación semántica.

\section{PROCESOS MORFOLÓGICOS}

Cabe comenzar por señalar que a este tema la Nueva gramática le dedica el mayor número comparativo de páginas por la diversidad de ejemplos correspondientes a las diferentes normas cultas vigentes en los países de habla española. Hay, en efecto, una gran distribución geográfica respecto del uso de las variantes existentes. En cuanto a la doctrina que presenta la Nueva gramática de la lengua española, se reconocen como procesos morfológicos en la formación de nuevas palabras solo los procedimientos de derivación y composición, con una redistribución interna de sus contenidos que se aleja bastante de la tradicional, siguiendo de este modo planteamientos de la lingüística contemporánea. En efecto, en el concepto de derivación a partir de las bases léxicas de palabras existentes en nuestra lengua no solo se incluye, como era lo tradicional, el mecanismo de sufijación, sino también el de prefijación, que formaba parte de la composición de palabras. De acuerdo con la actual doctrina, las palabras pueden ser derivadas por sufijación y también por prefijación. Y aún más, en el acápite dedicado a la derivación verbal, la Nueva gramática incluye uno de los mecanismos de parasíntesis tradicional, el proceso que permite formar nuevos verbos por afijación discontinua, esto es, mediante un afijo llamado discontinuo porque simultáneamente se antepone a la base léxica a la vez que se le pospone, del tipo de a...ar (alargar), a...ear 
(apalear), a...izar (aterrizar), a...ecer (anochecer), o bien, en...ar (encarcelar), en...ecer (entristecer), modelos que de hecho corresponden a los de mayor productividad. Incluso se registran unos cuantos ejemplos formados por derivación mediante prefijación y sufijación simultáneas, que también se incluían en el proceso de parasíntesis, como el sustantivo empanada y los adjetivos desalmado, anaranjado, aseñorado, acromado (usado en pintura) y adintelado (usado en arquitectura), y algunos otros de carácter coloquial y de extensión más bien dialectal, como apapayado y amermelado, en Chile verdaderos eufemismos de abuevonado, que se dice de una persona ingenua y fácil de engañar e, incluso, de manipular. Con esto, la tradicional parasíntesis viene a desaparecer $\mathrm{o}$, a lo más, a quedar reducida al menguado mecanismo — dada su poca productividad — de juntar una palabra a la base léxica de otra, añadiéndole a la vez un sufijo, esto es, composición y derivación aplicadas simultáneamente. Entre los ejemplos, que apenas pasan de una docena, hay incluso algunos prácticamente en desuso o de muy escaso uso como misacantano, ropavejero, barriobajero y picapedrero; otros se mantienen tradicionalmente vigentes como sietemesino, quinceañero, pordiosero; algunos son de formación más reciente como machibembrar, centrocampista y largodistancista (empleado en Chile para designar a quien frecuentemente hace llamadas telefónicas de larga distancia); otro que se suele incluir, pero cuya ubicación en esta categoría merece serios reparos, es cuentacorrentista, que se formaría a partir de la locución nominal cuenta corriente. También hay uno que otro ejemplo de reciente creación como hispanounidense o como el que pone el escritor Alberto Fuguet en boca del protagonista de su novela Tinta roja: "Mi mirada provinciana y clasemediera".

Por otra parte, se reemplazan los conceptos de derivado homogéneo y heterogéneo, según procedan de palabras de la misma o desigual clase gramatical, por los conceptos de denominal, deadjetival y deverbal, según que la palabra estudiada provenga de un sustantivo, adjetivo o verbo, respectivamente.

En cuanto al procedimiento formal de composición, se reconocen tres grandes categorías: los compuestos propios o léxicos, los compuestos sintagmáticos o pluriverbales y los compuestos neoclásicos y mixtos. 
Los compuestos propios o léxicos corresponden a las clásicas palabras compuestas en que dos de ellas — ambas nativas - se fusionan en una sola palabra ortográfica, del tipo de rompeolas, pelirrojo, claroscuro, malsonante, limpiaparabrisas. Su vigencia se manifiesta en la constante creación de nuevos compuestos como metrotrén o metrobús.

En el caso de los compuestos sintagmáticos o pluriverbales se distinguen los que se escriben con guion y los que no lo llevan; en ambos casos los términos conservan su independencia gráfica y acentual. Los que forman palabras compuestas con guion suelen corresponder a adjetivos que se aplican a referentes que contrastan o que al menos mantienen su autonomía, del tipo de una empresa chileno-peruana, un convenio bispano-alemán, un proyecto físico-químico. Por su parte, los compuestos sintagmáticos sin guion podrían ofrecer y de hecho ofrecen cierta confusión con las locuciones nominales. Según nuestra propuesta, se caracterizan porque su primer componente es un sustantivo de cuyo referente el segundo expresa una característica o una función o finalidad, lo que se puede apreciar en los siguientes ejemplos: tren bala, sala cuna, departamento piloto, cabeza rapada, piel roja, dulce de leche, etc. En las locuciones nominales, en cambio, el grado de lexicalización es mucho mayor, de modo tal que conforman una sola unidad léxica, aunque no ortográfica, como en ejemplos del tipo de mesa redonda, manjar blanco, ratón de biblioteca, dedal de oro.

En cuanto a la composición neoclásica, esta corresponde a palabras compuestas que se forman por la unión de bases compositivas cultas o clásicas (griegas y latinas). Estas bases o elementos compositivos (raíces, prefijos y sufijos) tienen la particularidad de no ocupar siempre una posición fija, así en filólogo y logopedia, filósofo y pedófilo. Además, pueden dar lugar a nuevas voces en combinación con un afijo también culto, como en crónico, étnico, hídrico, etc. Interesante de mencionar es el caso de creación que se ha dado, al menos en Chile, a partir del término homicida como modelo, de una nueva palabra: femicida, usada como norma ya establecida para significar el asesinato de una mujer por parte de su marido o conviviente. 
Por su parte, los compuestos mixtos combinan elementos compositivos cultos con elementos compositivos nativos, procedimiento sumamente productivo, como se puede apreciar en musicólogo, cineteca, fotocopia televisión, portavoz, por nombrar solo algunos.

\section{PROCEDIMIENTOS POR REDUCCIÓN}

No consideraremos en este apartado esos casos de derivación que podríamos llamar regresiva, puesto que se produce el fenómeno inverso a la natural expansión que supone, en la inmensa mayoría de ellos, la derivación; casos que quedan ilustrados con ejemplos tales como retén de "retener" y sostén de "sostener". Tampoco nos referiremos a los numerosos casos de acortamientos y de abreviaturas, actualmente en uso y en plena producción por quienes se comunican a través de los diferentes medios electrónicos y que configuran extensas redes sociales de intercambio. La lexicografía de un futuro no muy lejano deberá estudiar el tema y sopesar su incorporación en diccionarios, tal vez especializados. Nos detendremos, en cambio, a señalar cinco procesos de reducción propiamente tales, con ejemplos que en algunos casos ya han sido incorporados al diccionario oficial y otros que ya fueron registrados en diccionarios regionales o locales o, incluso, se encuentran a la espera de su incorporación.

a) Acortamientos. Algunos son de carácter panhispánico como foto, bici, bus, auto, metro, disco, tele, profe; otros, de uso regional como mano de hermano (México), el cual se emplea para nombrar a un amigo cercano. En Chile, con el mismo significado, aunque de carácter popular y más bien humorístico, tenemos cumpa de compadre, término que, entre otros, se ha exportado a países vecinos a través de Condorito, personaje de un cómic. También de uso al menos local en Chile, y de carácter coloquial, son los casos de cleta por bicicleta, secre por secretaria, dire por director(a) e, incluso, porfa, reducción absolutamente informal de la locución de cortesía "por favor".

b) Abreviaturas. Solo para efectos de escritura, incluyo únicamente las que me ha sido habitual usar en mi calidad de secretario de la Academia Chilena. Entre estas, las abreviaturas correspondientes a usted, $U d$;; 
señor, $S r$; señora, Sra.; doctor, $D r$; doctora, Dra., y sus correspondientes plurales. A las anteriores agrego las abreviaturas ortográficas de don y doña, $D$. y $D \tilde{n} a$., respectivamente, y las correspondientes a la palabra etcétera, etc. y a las expresiones "post data", $p . d$. y "que en paz descanse", q.e.p.d.

c) Siglas. Entendidas como las define el diccionario oficial, esto es, como "Palabras formadas por el conjunto de letras iniciales de una expresión compleja usada..." y que tanto abundan en nuestro tiempo. Las hay de carácter panhispánico como ONU, UNESCO, CEPAL; otras, en cambio, son propias de cada región e incluso de cada país, como $A V E$ en España para nombrar un tren de alta velocidad. En Chile, solo por mencionar algunas, citaremos $L A N$ (Línea Aérea Nacional), CUT (Central Única de Trabajadores), UC para referirnos a la Universidad Católica de Chile y USACH para la Universidad de Santiago de Chile. Interesante de señalar es el caso de las siglas que han dado origen a sustantivos comunes, algunos ya registrados en el diccionario oficial y otros por registrarse, tales como ovni (objeto volador no identificado) que procede de un calco de la sigla en inglés UFO; sida (síndrome de inmudeficiencia adquirida), palabra de la que deriva sidoso (a); y de muy reciente aceptación la palabra vip, de la sigla en inglés "very important person", para referirnos a ciertos lugares o salones reservados a personalidades destacadas.

d) Acrónimos. Entendidos solo en la segunda acepción que registra el diccionario oficial, esto es, como "Vocablo formado por la unión de elementos de dos o más palabras, constituido por el principio de la primera y el final de la última”. Ejemplos tales como portuñol, espanglish, cantautor, motel, Mercosur, ilustran el concepto. Pero hay que señalar que también se registran muchos otros términos que se mueven entre los conceptos, como MINEDUC (Ministerio de Educación) y CODELCO (Corporación del Cobre): siglas, pero no solo de letras iniciales, y acrónimos, pero no solo de la combinación de la primera sílaba de la primera palabra con la última de la segunda.

e) Hipocorísticos. Entendidos en el marco de estos procesos de reducción solo como las formas abreviadas de los nombres propios que se 
usan como designación cariñosa o familiar. Así en Rafa por Rafael, Bea por Beatriz, Lupe por Guadalupe, Sole por Soledad, Tato por Fortunato, entre tantos otros.

\section{CASO DE EXTRANJERISMOS}

La incorporación de términos procedentes de otras lenguas ha sido y sigue siendo habitual en el enriquecimiento del léxico de toda lengua. En efecto, es un hecho histórico que las lenguas acogen, en calidad de préstamos en un comienzo, el léxico correspondiente a la cultura de los países que ejercen hegemonía en determinadas áreas. Constituye este proceso la vía externa por la cual nuevas palabras enriquecen el caudal léxico de una lengua. Nuestra lengua española o castellana no es una excepción y su léxico patrimonial procedente del latín y del griego (este por medio del primero), se ha visto incrementado por constantes préstamos — considerados ya clásicos - que proceden, en calidad de elementos compositivos cultos, de las dos lenguas anteriormente nombradas - griego y latín - y, en calidad de vocablos asimilados, del árabe, del italiano y del gran aporte de las lenguas indígenas de América $\mathrm{y}$, sobre todo en los tiempos actuales, de dos lenguas modernas como son el francés (siglos XVIII y XIX) y el inglés (siglos XIX, XX y XXI).

Estos préstamos, generalmente léxicos, que una lengua toma de otra y también reciben el nombre de extranjerismos. Se suelen introducir primero en forma cruda, es decir, conservando la ortografía y aproximadamente la misma pronunciación de la lengua de la cual proceden. En la mayoría de los casos, terminan siendo asimilados por la lengua meta, integrándose en ella ortográfica y fonéticamente.

Por mencionar solo algunos ejemplos de voces de origen extranjero — del francés y del inglés — ya asimiladas a nuestra lengua y que se encuentran registrados por el diccionario oficial, destaco en el caso del francés los términos bidón, lentilla, carné, chalé y garaje; los tres últimos escritos y pronunciados en forma cruda hasta hace unas décadas: "carnet", "chalet" y "garage". Del inglés resalto suéter (usado en Chile), jersey (empleado en España), estándar y su derivado verbal 
estandarizar, fútbol, láser, computador, y tantos otros pertenecientes a las áreas del deporte y de las ciencias y tecnología. En cambio, no figura en el diccionario oficial el término queque (bizcocho) de uso común en Chile, tomado del inglés cake, pero ya asimilado al español. Tampoco se registra en el diccionario el término de origen alemán kuchen (bizcocho cubierto de fruta en la parte superior y puesto al horno), verdadero chilenismo que nuestros conciudadanos prefieren mantener en su ortografía original, a la vez que con pronunciación alemana; caso similar al de wisky, cuya propuesta académica "güisqui" ha sido mayoritariamente rechazada. También es interesante mencionar el caso de otro chilenismo, el término lonchera (fiambrera o recipiente para llevar comida), escrito y pronunciado con vocal $\left.<_{0}\right\rangle$, pero que procede por derivación de la palabra inglesa lunch.

En cuanto a anglicismos crudos, bien sabemos que sobreabundan en nuestra prensa y en publicidad comercial y turística. Así "zaping", "lobby", "mall" y "resort", por mencionar solo algunos que se mantienen en su escritura original. Mención aparte merece el caso de "resort", término al que se ha propuesto últimamente cambiar por el compuesto sintagmático centro vacacional (esta sugerencia proviene de la Fundación del Español Urgente-Fundéu BBVA, que trabaja en Chile asesorada por la Academia Chilena de la Lengua). Creemos que difícilmente tendrá éxito dicha propuesta, porque la expresión centro vacacional se usa actualmente, al menos en Chile, para designar ciertos lugares de descanso que mantienen las Cajas de Compensación y que carecen de la connotación socioeconómica de los actuales "resort", de su ubicación en lugares privilegiados en que se suelen instalar, como también de los servicios sofisticados que en ellos se ofrecen. Semejante es el caso del compuesto sintagmático centro entretencional, con que se nombran aquellos lugares de descanso que ofrecen algunas municipalidades de provincia para personas que no cuentan con muchos recursos económicos. Mejor éxito, en cambio, está teniendo el compuesto centro comercial, que convive con el préstamo "mall". Tanto las Academias de la Lengua como los lexicógrafos y demás especialistas se ven, pues, obligados a considerar estos factores extralingüísticos en el momento de tomar decisiones. 
Dentro del tema de los extranjerismos han de tenerse también en cuenta los posibles nuevos calcos semánticos tales como los ya incorporados baloncesto, balompié, sudadera, disco compacto, disco duro, banco de datos, y el simpático ratón, que se usa a lo menos en España y no así en Chile en lugar del término en inglés "mouse", escrito y pronunciado como en la lengua original y, por ello, un auténtico extranjerismo crudo.

\section{FIJACIÓN LÉXICA}

El procedimiento de fijación léxica o de lexicalización de determinadas construcciones sintácticas da origen a las así llamadas "locuciones", que reciben también el nombre de "palabras complejas" e, incluso, de "lexías pluriverbales". También este procedimiento constituye una vía normal con que la lengua incrementa su léxico, pero ante este tema se percibe en primer lugar cierta diferencia por una parte entre las expresiones con un mayor grado de gramaticalización como son las locuciones verbales del tipo de darse cuenta, echar a perder, venirse abajo; las locuciones adverbiales del tipo de en el acto, de repente, por si acaso; y las locuciones preposicionales del tipo de a través de, en medio de, con objeto de, entre otras, y, por otra parte, las locuciones nominales del tipo de mercado negro, ratón de biblioteca, ojo de buey, mesa redonda, manjar blanco, oreja de oso, dedal de oro, etc., las que se perciben como locuciones con un menor grado de gramaticalización que las anteriores. Además, como ya lo señalábamos, no siempre resulta fácil establecer lo que las diferencia de los compuestos sintagmáticos sin guión, como por ejemplo la diferencia que se debe considerar entre cabeza de turco (locución nominal) y cabeza rapada (compuesto sintagmático) o entre manjar blanco (locución nominal) y dulce de leche (compuesto sintagmático).

\section{CREACIÓN SEMÁNTICA}

La creación de léxico tanto por uso metafórico, por cambio de categoría gramatical o por aportar un nuevo significado - humorístico o tabú-a palabras ya existentes constituye una vía de constante enriquecimiento que el especialista no puede desconocer. Así, hablamos con toda propiedad en sentido metafórico de dar luz verde a un proyecto, de descongelar 
los salarios, del abanico de posibilidades que se nos ofrecen; o cambiando la categoría gramatical de adjetivos y de sustantivos le deseamos a alguien que lo pase estupendo o que lo pase chancho o bomba; o bien atribuimos otro significado a palabras existentes, basándonos en la similitud fónica, y decimos de una persona que es lenteja por ser muy lenta o que es o anda califa por ser fácilmente excitable, sexualmente hablando. Existen muchas otras expresiones nuevas que nos sorprenden constantemente como etcéteras cosas, dicho por un niño durante una disertación escolar y que hoy se utiliza en determinados ambientes; o miré por la ventana y como que estaban desplumando gansos, refiriéndose un trabajador de un pueblo precordillerano al momento en que se había puesto a nevar.

\section{PALABRAS FINALES}

Hasta aquí una mirada a vuelo de pájaro de un tema que, sin duda alguna merece una atención mucho mayor, y cuya presentación en este congreso no ha tenido otra pretensión que hacer presente, una vez más, a quienes se especializan en la elaboración de diccionarios y en el estudio del léxico en general, como también a quienes orientan en el uso adecuado de nuevos términos - miembros de Academias de la Lengua y profesoresque se deben tener siempre presentes las distintas vías por las que nuestro léxico se incrementa constantemente y estar alertas a las nuevas voces que surgen para sopesar el momento en que deban quedar registradas junto a las de más larga y probada trayectoria.

\section{Correspondencia:}

José Luis Samaniego Aldazábal

Miembro de la Academia Chilena de la Lengua.

Correo electrónico: acadchileng@terra.cl 